\title{
Communicative and Pragmatic Peculiarities of Metalinguistic Comment of Semantic Ambiguity in Financial Crisis Reports within Journalistic Economic Discourse ${ }^{1}$
}

\author{
Serebryakova Svetlana Vasilyevna
}

\author{
Sidelnikova Ekaterina Alekseevna
}

Federal State Autonomous Educational Institution for Higher Professional Education "North-Caucasus Federal University"
E-mail: svetla-na@mail.ru,Email: e.sidelnikova_7@mail.ru

Doi:10.5901/jesr.2015.v5n2p73

\begin{abstract}
In the given article the communicative and pragmatic specific character of dysphemisation strategy that generates pragmatically relevant information and that is used in JED as a metalinguistic reflecsive was determined. Three degrees of information generation in the order of explicit and emotional meaning weakening of a context are revealed.
\end{abstract}

Keywords: journalistic economic discourse, communicative pragmatics, financial and economic crisis, dysphemisation strategy, information, degree of dysphemisation, metalinguistic reflecsives.

\section{Introduction}

The economic discourse as a form of text activity of a special pragmatic orientation doesn't lose its dynamic character. It transmits not only information on changes in the financial and economic sphere, but also peculiarities of processes of its representation at cognitive and semantic level. Taking into account the economic events that the world community is suffering in the last decade, the functional and pragmatic research of the financial and economic crisis narrative is actual and in demand. This narrative is reported in different ways by mass media of the USA and the European countries.

In this regard, choice of communicative and pragmatic research acpects of dysphemization process is caused not only by special attention of mass media to economic events, but also by the necessity to study various ways of information coding in the journalistic economic discourse, to identify ways of manipulative impact on the wide audience.

The objective of the research is to reveal communicative and pragmatic peculiarities of dysphemization process on the basis of the journalistic economic discourse material.

300 contexts from print and electronic versions of newspapers in English were used as practical material for the research: The Guardian, The Observer, The USA Today, The New York Times that discuss the certain phenomenon the financial and economic crisis from 2010 to 2012.

\section{Definition of the Journalistic Economic Discourse}

The idea of a discursive formation is the basis of understanding of a discourse as the integrative group of texts connected by the semantic relations and / or united taking into account the communicative and functional and objective relation. In this case "the characteristics that form a discourse, i.e. texts selection criteria that are the empirical basis to study the discourse of this or that type, are spheres of human communication and practice, areas of knowledge, text typologies, etc." (Chernyavskaya, 2006: 21).

In linguistics the term "discourse" starts being used in the meaning that is close to the term "functional style" (Tolpygina, 2002: 76) or it is treated as the formula "text + situation" (Makarov, 2003: 87). The national school of linguists presented by V.G. Kostomarov and N.D. Burvikova, opposes a discurssion (the text expansion process in consciousness of a recipient of the information) and a discourse (result of perception of a text when the perceived sense coincides with a plan of the sender of the text) (Kostomarov, Burvikova, 1999: 10).

In our opinion among many definitions of the discourse singled out by scientists the most precise definition to

\footnotetext{
${ }^{1}$ Supported by the Russian Foundation for Humanities (RGNF). "Tolerance as a competence component of communicatively flexible
} linguistic personality in the conditions of multicultural region of North Caucasus", Project № 15-04-00126 
describe its peculiarities is the following: "the discourse is the cognitive phenomenon, i.e. dealing with transfer of knowledge, operating of special type of knowledge and, the main thing, with creation of new knowledge" (citation of Kubryakova, 2000: 23). Hope that it (knowledge) will be adequately perceived by the addressee, "is based on belief in creative abilities of the addressee, in his ability to perceive a text not as the literal instruction, but as something that allows to reconstruct architecture of modelled knowledge" (Mikeshina, 2008: 23).

T.A. Van Dijk thinks that "discourse, in the broad sense of the word, is a complex unity of language form, meaning and action that could be characterized in the best way by means of communicative event or communicative act, discourse is not limited by the concrete language statement", "more likely, it is complex communicative phenomenon that includes social context providing the idea of communication participants (and their characteristic), as well as processes of production and perception of a message" (Van Dijk, 1989: 112).

V.Z. Demyankov's concept of the discourse is of interest for our research. Demyankov notes its concentration around the basic concept: "Discourse - a discourse, any fragment of a text consisting of more than one sentence or an independent part of a sentence. Often, but not always, it concentrates around some basic concept; creates the general context describing characters, objects, conditions, time, acts, etc., it is defined not by sequence of sentences, but by the world that is common for both the creator of a discourse and its interpreter, the world "is under construction" durig expansion of the discourse" (Demyankov, 1982: 7).

It should be noted that V.Z. Demyankov emphasizes an intentional component of the discourse, because in this case one can say about interpreter's opportunities, i.e. about intentional space and an interpretation context. At the same time, the discourse, according to the author of the definition, has logical structure: "The initial structure for the discourse looks like sequence of elementary pro-positions connected with each other by the logical relations of conjunction, disjunction, etc. Elements of discourse: a) conditions accompanying the events; b) background explaining the events; c) assessment of participants of the events; d) information correlating the discourse with the events" (citation of Stepanov, 1995: 37-38). The intentionality as demonstration of subjectivity forms "the vector of discursive processes that allows the discourse system to become the reality" (Danilova, 2001: 51).

For this research S.V. Gusarenko's opinion is also important. He emphasizes the communicative nature of the discourse, representing it as "some temporary communicative formation, a frame, a focalized fragment that, moving within the text, forms the cognitive structure among a reader, a listener. The structure should theoretically reflect all communicative message - all text or all conversation" (Gusarenko, 2007: 22).

On the basis of the discourse-objects the following should be singled out in the theory of discourse-analysis: 1) discourses of household communication (friendly chats, rumours, household conflicts, etc.); 2) academic discourses (discourses of scientific communities, discourses of science and humanities disciplines); 3) institutional discourses (administrative discourse, office discourse, bank discourse, pedagogical discourse, medical discourse, army discourse, church discourse, etc.); 4) political discourse (discourses of political ideologies, discourses of political institutions, discourses of political actions, etc.); 5) marketing discourses (advertizing discourse, discourse of sales, consumer discourse, service discourse, etc.); 6) media discourses (TV-discourse, cinema discourse, discourse of advertizing, etc.) ; 7) discourse of business communications (discourse of business negotiations, discourse of business communications), etc. (see works: Dijk, 1998; Ilyin, 1997; Pecheux, 1999; Fairclough, 2008; Sheigal, 1998; Chilton, Schaffner, 1997; Torfing, 1999, etc.).

Within the political discourse the Russian researchers also mention the economic discourse (hereinafter - ED), but to define it they often use the hyperonym "business discourse". As an independent type of discourse E.Yu. Makhnitskaya characterizes ED as set of all speech acts used to describe and characterise the economic realities. By ED the author understands oral and written fragments of the text and the whole texts reproducing the economic practice (Makhnitskaya, 2002: 159). ED is also pointed out in the thesis and other works by A.Yu. Klanshchakova who describes subject, objectives of communication and participants of the economic discourse (Klanshchakova, 2002). E.D. Stepanova gives ED the following definition "interactive cooperation of participants of communication in the sphere of the financial and credit, tax, commercial, entrepreneurial relations" (Stepanova, 2006: 436).

This type of discourse can be classified as the institutional one, as ED can be considered at least from two positions: social (the state - economic, financial departments; institute of economics - a student of financial and economic department; a seller - a buyer) and discursive (verbalization of the status focused communication between, for example, the president, politicians-economists and the people, which basic concepts are: "goods", "money", "market", "export", "import", "economy", etc.).

In our opinion ED is the specialized interaction of communication participants that concentrates around basic economic concepts and creates general / situationally specified social and economic context, including ideological, 
social, psychological factors, system of cognitive and pragmatic plans of a sender who interacts with an addressee both to optimize economic activity, and to form public opinion.

The dominant subject of ED is set by knowledge of the economic situation, possession of an information field in this sphere (that allow increasing efficiency of both private and state enterprises, to regulate production process, cash flows, to provide effective economic activity). Materials of messages, articles in public / professional magazines / newspapers, regulatory documents, the Internet sites, economic forums of G-20 summits with reports on the economic situation can become the source of such knowledge.

The journalistic discoursion is traditionally treated as "set of the language means serving the sphere of mass informing on topical, first of all, social and political issues" (Kuznets, 1969: 5). Selection and functioning of language means is defined by features of the journalistic text existance. Any issue of a newspaper, any TV or radio piece of reporting has many subjects and they are oriented on the wide audience. It explains orientation of journalistic texts on both general vocabulary, and special vocabulary (political, economic, medical, etc.) by means of which it is possible to inform on everything that interests the audience.

Existence of ED in the journalistc texts lets us speak about the concept of "journalistic economic discourse" (hereinafter - JED) and give the following definition: the type of a discourse presented by the integrative group of journalistic texts, connected by the content devoted to the economic problem, united taking into account communicative and functional and objective relation, reflecting with estimation / indirectly ferlecting (through a journalist / expert in economy) regarding actual economic events and socially significant phenomena for the purpose of impact on the mass addressee and formation of public opinion.

It should be also noted that JED can vary its realization by journalists and by means of journalists through the editor's activity - the expert who prepares materials for publication, that are intended for both persons with economic education, and wide reading audience or its part who want to be informed about the events at the state level, but who do not have special background. Degree of freedom of information presentation by a journalist depends on the relation of the periodical to the policy realized by the state (support of points of view and the conducted policy / neutral relation / opposition).

\section{Pragmatic Aspects of Communication}

S.V. Gusarenko notes that "cognitive and procedural approach to interpretation of speech during discursive interaction demands separate understanding of the discourse, on the one hand, as the typological version of speech with all variety of its sociocultural and communicative and pragmatical parameters and, on the other hand, as the fragment of speech in its cognitive representation, in communicative function at each certain moment of discursive interaction" (Gusarenko, 2007: 17).

Discourse as communication derivative - complex interpretive process, which by definition can't be characterized as rectilinear. It is due to the fact that in the process of communication meanings of language units aren't transmitted by "a sender" to "a recipient" as such, they are created by a listener on the basis of the situation in which communication is carried out and his language experience, i.e. "one needs to speak about spontaneous semiosis" (citation of Sidelnikova, 2011: 14). Meanings aren't in words, they appear in consciousness of a listener as the result of interpretive efforts (Arkhipov, 2001: 31).

A lot of things in speech communication can't be explained without appealing to changes in the extralinguistic reality, speed of which increases every year. Such changes lead not only to emergence of new words, notions, concepts and disappearance of old ones, but also to noticeable, not always predictable changes in semantic filling of words, form of which is invariable. "Discursive peculiarities of reality are as the semiotics system, decoding of which allows us, speakers of modern languages, to transmit information and to gain desirable perlocutionary effect, to be active and successful people in the world" (Khutyz, 2010: 6).

The semantic space becomes more plastic, and its research and description in the actual condition is more important as such description will allow to predict realization of latent semes in this or that context and emergence of the senses hidden for some groups of native speakers and obvious for others (Butorina, 2007: 128).

Variative nature of understanding and interpretation of information, implied content of economic discourse in journalistic text space is caused by relevance of such phenomena, as presupposition, background knowledge, subtext, implicit sense, connotation. "These notions describe not relations between separate sentences and their parts, but actions of participants of language communication as relevant aspects of interaction between communicants with each other and with the world, as collective actions that allow to distinguish personally caused senses in a social context. In 
addition it is impossible to underestimate the role of explicit components that are necessary to make conclusions of general sense of components" (Makarov, 2003: 160).

Pragmatic presuppositions are background knowledge of communication participants. They are the integral element of text interpretation. In the broad sense such background knowledge includes data on cultural and historical context of the concrete age, certain facts of society life, events related to creation of this or that text. On the basis of implicit semantic meaning it is possible to assume that presuppositions are a subtext.

The subtext is "that true (author's, deep) sense of a statement (text) that is not fully expressed in a text, but that is actually there, it can be opened and understood in case of the concrete analysis and the communication situation, communication structure" (Kozhina, 1979: 63). It is possible to distinguish a subtext by means of language indicators that provide access to implicit information:

a) words and word combinations according to which the recepient can guess the implicit content;

b) sentences or parts of a text when the expressed message makes a reader understand implicit information;

c) text as a whole when it is associated with the secondary implicit sense or text (Vinogradov, 2001: 41).

The main functions of the subtext are: 1) text formation (establishment of associative and semantic connection between parts of a text, formation of its semantic unity); 2) informative (realization of the main idea of a text); 3 ) pragmatic (impact on a reader / listener); 4) transfer of a text modality (relation of an author to the described event of reality) (see works: Ovsyannikova, 1993; Vladimirova, 2003; Dolinin, 2007, etc.).

Implicit senses are also found in the vertical context which is meant the implied historical and philological information in the text of a message. Such categories, as allusion, quotation, symbol, realities, idiomatics, etc., are inherent in the vertical context. The vertical context can conclude the implicit information that is caused by the language and doesn't depend on intentions of the author of the message (Gyubbenet, 1981: 78). Such tendency is also characteristic of phraseology, words-realities and various idiomatics which by their nature are connected with the background information. Thus, the ratio of concepts of a context, background knowledge and presupposition significant for our research can be treated as: the context is an implicit part of the content of the text, formed by preliminary data, i.e. presupposition which structure includes background knowledge.

Connotations, i.e. stylistic, emotional and semantic shades that accompany words don't exist as such, they usually concentrate in a word that has its material and semantic content, and they are imposed on one of its meanings. However in any case it is necessary to emphasize originality of many connotations in which peculiarities of culture of this or that ethno-linguo-social community, i.e. background information, are presented (citation of Vinogradov, 2001: 39).

In the text theory the proposition is mainly understood as the main idea of a statement, the main information. Propositional links of the statement characterize, first of all, logical and semantic relations between objects and phenomena, their temporal and spatial parameters, modality, theme-rheme division and illocutionary purpose of the statement (Susov, 2006).

To determine adequate sense of the very communicative variants, that are relevant for each concrete speech act, is more essential for communicative linguistics. It is necessary to note that interlacing of the main components of a text consists in presuppositions of the subtext. Components of presuppositions are background knowledge and connotations of implicit, hidden, implied information.

Taking into account the above stated it is possible to claim that decoding of senses of the statement is performed in the text as the whole unity, not in its "anatomic" parts, including level of the statement. The emphasis in this case is not on the sense of the statement as such, but on its participation in development of main publicistic idea. Such approach allows to understand and interpret a text in harmonious interaction of two plans of its content - open, expressed by explicit morphological, lexical, stylistic, syntactic means, and hidden, expressed by implicit means, by means of usage of potential values of language units and composition components (Kayda, 2006: 39).

\section{Degrees of Dysphemisation Realized in JED Devoted to Financial and Economic Crisis}

We shall note that scientists define the field of rational and logical linguistic consciousness that is aimed at reflection of natural human language as an element of the actual world, as "metalinguistic consciousness", "linguistic consciousness", "metalinguistic knowledge", "linguistic reflection", "metalinguistic activity" (see works: Gasparov, 1996; Yeyger, 1990; Nikitina, 1989; Rostova, 2000; Khlebda, 1999).

According to E.I. Sheigal "the secret that is in the context is disclosed through answers on the merits of the case, explicit descriptors of "the answer" (an answer, a background, to give a prompt, to decipher, to mean, to interpret, to show trump cards) and also specific speech acts - metalinguistic reflecsives. The purpose of a reflecsive is to remove 
information entropy, to change a message to make it more precise, true". The researcher treats a reflecsive as any act of metalinguistic commenting of the speech facts of both a speaker and an interlocutor. As metalinguistic operators of interpretation in reflecsives are the following words and phrases: actually it means; the so-called; that is called as ...; the sense is that ...; to interpret as; id est; be more precise; actually it is necessary to understand as, and also the adversative structure: not X, but $Y^{\prime \prime}$ (Sheigal, 2002: 133).

M.A. Kormilitsina notes that "during the era of changes when the old things are being destroyed, and the new things are not created yet, not defined, many reflecsives represent thoughts of an author on the accuracy and adequacy of nominations used to describe a situation" (Kormilitsina, 2000: 21).

T.I. Vepreva's research shows that reflecsives can be presented in various text forms as: 1) canonic textreflecsive, separate product of speech; 2) reflecsives inside the whole text: a) in the form of the author's associated remark, the verbal speech, the note, making comments on the main text, b) in the form of the metalinguistic statement; 3 ) in the form of the chain of the interconnected statements - the text fragment (Vepreva, 2005: 75).

According to our research the reflecsives in JED can be presented by means of the explicit dysphemistic contexts containing an economic dysphemism that we treat as a word or an expression appearing as a result of pragmatic information processing to draw readers' attention to undesirable / forbidden concept that was veiled earlier, to give negative and revelatory meaning to an economic event, to strengthen expressiveness of a speech, to provide desirable pragmatic effect and to make purposeful impact on a reader.

It is necessary to add that this phenomenon, "the economic dysphemism", in our opinion, corresponds to dysphemisation strategy as the process of pragmatically relevant information generation in texts of a journalistic economic discourse.

It should be noted that the key concept for our research is a strategy that is understood as "set of speech actions" from the pragmatic and linguistic point of view (Trufanova, 2001: 58), "a chain of speakers' decisions, his choice of certain communicative actions and means of language" (Makarov, 2003: 192).

In the order of weakening of explicit and emotional meaning of a context with dysphemistic sense and taking into account the above stated cognitive components we define the first degree of dysphemisation as follows: "direct dysphemism-nomination of the object of a statement with a negative connotation"; the second degree as: "presupposition + dysphemistic-contextual comment of the author of a message"; the third degree as: "understanding of dysphemistic negative information".

Let's show our observations on the material of "crisis" narrative realized in JED. According to A.P. Chudinov, that we share, the narrative is characterized by thematic unity, common main "heroes", common event outline, temporal and spatial isolation, however its spatial and temporal localization isn't absolute (Chudinov, 2006: 78). D. Schiffrin defines the narrative as "a form of discourse by means of which we reconstruct and represent the last experience for ourselves and others" (Schiffrin, 2006: 321).

In the $19^{\text {th }}$ century the classical definition of crisis as such ("not desirable and dramatic phase in capitalistic economic system, that is characterized by fluctuations and the negative phenomena, hindrances") (Pilipchuk, 2003: 5) was replaced by more concrete concept "economic crisis". According to F. Machlup, one can speak about economic crisis in case if "there is undesirable condition of economic relations, intolerable critical situation for many strata of population and manufacturing branches of economy" (Machlup, 1934: 559). V. Sombart defines the economic crisis as "economic negative phenomenon during that there is a danger to economic life, reality in all spheres" (Sombart, 1904: 23-26).

We believe that the economic course of development, chosen by the "western" countries, was initially doomed to failure (huge loans, high percentage without change of living standards) and as at each next stage since 2010-2012 the situation is more aggravated, it makes no sense for mass media to block evidence of the facts of dramatic changes of economic climate because the current situation directly influences the population's living standards. Thus, we assume that growth of necessity of pragmatically relevant information generation that can be realized by means of dysphemisation strategy as a reflecsive in JED will be observed.

For instance, the first context that confirms the above stated situation, is taken from the analytical article headed "Germany's Angela Merkel and other European leaders is under increasing pressure over the Greek debt crisis going global as markets were in turmoil". Using the debt contagion metaphor to realize the first degree dysphemisation strategy that transfers the direct dysphemism-nomination of the object of a statement with a negative connotation (infection, poison), the author of the article avoids semantic uncertainty and represents information in the unveiled form. In terms of pragmatics the purpose to take partially responsibility off the European countries for economically unstable situation in the world and to shift the blame to Greece is realized: 
The growing crisis in the eurozone threatened to undermine the global economic recovery as markets plunged across the world on fears that European leaders may not be able to contain the debt contagion spreading from Greece («The Guardian», 2010 May 7th).

The adjective growing describes the crisis as the event that gathers pace and it is used in the sentence as the reflecsive; the phrase threatened to undermine and the noun fears warn about possible consequences of financial and economic instability in the euro-zone.

The following context contains information on economic problems of New York, it is published in the analytical article headed "Unemployment claims, consumer prices jump" in the The USA Today, the second degree of dysphemisation is realized:

The Federal Reserve Bank of New York said factory conditions in that region worsened for a fourth month, according to its September survey. Businesses saw fewer orders and paid higher prices. Factories in the region employed fewer people and their remaining employees worked fewer hours, the New York Fed said (Unemployment claims, consumer prices jump, «USA Today», 2011 Sept 14th).

Referring to the data presented by the Federal Reserve Bank (the USA) and thus taking off responsibility for contents of the message, the author generates substantial and actual kind of information, i.e. omitting the parenthetical phrase be more precise the author presents it in the form of metalinguistic commenting and explains readers worse factory conditions (fewer orders and paid higher prices, employed fewer people, employees worked fewer hours). The message, which has been pragmatically strengthened by the elements of gradational comparison, contains implicit appeal to give material support to the business sector.

The third context published in The New York Times dated September 6, 2012 shows diffidence of the President of Germany on the economic stability of Italy and Spain that can destabilize the European Union. The author of the message doesn't veil these concerns, and generates them by means of reflecsive-dysphemisms with the negative shade of meaning: she worried, would overwhelm the European bailout funds, possibly sinking the currency.

Ms. Merkel's concern was that a bond speculators' run on Italy and Spain, the third-and fourth-largest economies in the euro zone, would overwhelm the European bailout funds. And that, she worried, would pose a fundamental crisis for the euro union, possibly sinking the currency (Huge Step Taken by Europe's Bank to Abate a Crisis).

The author's comment of Mrs. Merkel's words in the given way shows that information is stated by means of the second degree dysphemisation strategy.

\section{Concluding Remarks}

Thus, we determined communicative and pragmatic specific character of dysphemisation strategy that generates pragmatically relevant information and is used in JED as a reflecsive. In this research three degrees of information generation in the order of weakening of explicit and emotional meaning of a context ("direct dysphemism-nomination of the object of a statement with a negative connotation", "presupposition + dysphemistic-contextual comment of the author of a message", "understanding of dysphemistic negative information") are presented. This phenomenon depends on the information policy of both a publishing house and a political force, first of all, authorities in power, the reasons of financial and economic problems in this or that country, participation of the country in the current situation.

\section{References}

Arkhipov, I.K. (2001). The human factor in language: teaching manual. St. Petersburg: NIYAK.

Butorina, E.P. (2007). Hidden meanings: their reasons and research possibility. Hidden meanings in language and communication: Collection of articles. - M.: Russian state humanity university.

Chernjavskaja, V.Ye. (2006). Interpretation of scientific texts. Tutorial. Ed. Third, stereotypical. M.: KomKniga.

Chilton, P.A., Schaffner, C. (1997). Discourse and politics. Discourse Studies: A multidisciplinary introduction. T.A. van Dijk (Ed.). - Vol. 2: Discourse as Social Interaction. London: Sage, 206-230.

Chudinov, A.P. (2006). Political linguistics. M.: Flinta: Science.

Danilova, N.K. (2001). "Signs of the subject" in the discourse. Samara: Samara University Press.

Demyankov, V.Z. (1982). English-Russian terms in applied linguistics and automatic text processing. Issue. 2. Methods of analysis of the text. M.: Union Translation Center SCST and the USSR AS.

Dijk, T.A. van (1989). Language. Cognition. Communication. M.: Progress.

Dijk, T.A. van (1998). On the definition of discourse: http://www.nsu.ru/psych/internet/bits/vandijk2.htm.

Dolinin, K.A. (2007). Interpretation of the text. French. Ed. 3rd. M.: LCI Press.

Fairclough, N. (2008). Critical discourse analysis and the commodification of public discourse: universities. Discourse \& Society, Vol. 2 
(1), 170-185.

Gusarenko, S.V. (2007). Semantic structure of the discourse: the system and the entropy: monograph. Stavropol: SSU Press.

Gyubbenet, I.V. (1981). On the problem of understanding the literary and bélles-léttres text (English material). M.: Moscow University Press.

Ilyin, S.V. (1997). Words and Meanings. Experience description of the key political concepts. M.: Rus. political encyclopaedia.

Kayda, L.G. (2006). Compositional poetics of journalism: a tutorial. M.: Flinta: Science.

Khutyz, I.P. (2010). Actual communication practices: the context of reality in modern discourse pragmatics: Monograph. Krasnodar: Kuban State. Univ.; Education-South.

Klanschakova, A.Y. (2002). Problem of discourse typology on the example of economic discourse. Linguistic paradigms and didactics: Proceedings of the VII Intern. scientific-practical. conf., Irkutsk, 24-27 June 2002. Irkutsk, 67-75.

Kormilitsina, M.A. (2000). Reflexives in speech communication. Problems of speech communication. Saratov, $20-25$

Kostomarov, V.G., Burvikova, N.B. (1999). Precedent text as reduced discourse Language as creativity. Collection of articles on the 70th V.P. Grigorieva's anniversary. M.: IRYA RAS.

Kozhina, M.N. (1979). Stylistics of the Russian language. M.: International Relations.

Kubryakova, E.S. (2000). The concepts of discourse and discourse analysis in modern linguistics. Discourse, speech, speech activity: functional and structural aspects. M.: INION RAS.

Kuznets, M.D., Skrebnev, Y.M. (1969). Stylistics of the English Language. L.: State. Textbook. - Ped. Publ. Min. proev. RSFSR. Leningrad department.

Machlup, F. (1934). A Note on Fixed Costs. Quarterly Journal of Economics (QJE). Oxford. 48 (3), 559-564.

Mahnitskaya, E.J. (2002). On the current economic discourse. Speech activity. Text: Intercollege collection of articles. Taganrog, 158161.

Makarov, M.L. (2003). Fundamentals of the theory of discourse. M.: ITDGK "Gnosis".

Mikeshina, L.A. (2008). Epistemology and cognitive science: basic categories and principles of interaction. Group of authors. The cognitive approach. Monograph / Editor - RAS Academician V.A. Lektorskiy. M .: "Canon +" ROOI "Rehabilitation", 20-57.

Ovsyannikova, E.V. (1993). The main functions of the implicit meanings in statements and texts (based on the English-language prose): Author's abstract to thesis ... Candidate of Philology. St. Petersburg.

Pêcheux, M. (1999). Role of memory. In: Achard, Pierre et al. Role of memory (Nunes, J.H., Trad., And Intr.). Campinas: Bridges, $49-57$.

Pilipchuk, V.V. (2003). Crisis management: a tutorial. Vladivostok: Far Eastern State University TIDOT.

Schiffrin, D. (2006). In other words: Variation in reference and narrative. Cambridge: Cambridge University Press.

Sheigal, E.I. (2002). Reflexives in political communication. Theoretical and Applied Linguistics. Aspects of Metacommunicative activities I Interuniversity collection of scientific papers. Issue 3. Voronezh, 133-141.

Sheigal, E.I. (1998). The structure and boundaries of political discourse. Philologia. Krasnodar: Kuban State University, № 14, $22-29$.

Sidelnikova, E.A. (2011). On the dichotomous characteristics of some concepts of pragmatic context. Materials for 7 international scientific and practical conference "Education and Science for the XXI Century", 17-25 October 2011. Volume 8. Philosophy. Sofia: "Bel GRADE-B" LTD, 14-16.

Sombart, W. (1904). Die Bedeutung des Einschlags juedischer Elemente für Deutschlands. Wirtschaftsleben Ost und West: Illustrierte Monatschrift für modernes Judentum 4, 23-26.

Stepanov, J.S. (1995). Alternative world. Discourse. Fact and the principle of causality. Language and science of the end of the XX century: Collection of articles; ed. by Y.S. Stepanov. M., 33-73.

Stepanova, E.D. (2006). Pragmatic features of the communicative act "Loan Agreement" in economic discourse. Discursive aspect of linguistic units: monograph / Kostyushkin GM [and others]. Irkutsk: ISLU Press, 434-486.

Susov, I.P. (2006). History of Linguistics. M.: AST: East-West.

Tolpygina, O.A. (2002). Discourse and discourse analysis in political science. Political Science. M.: Institute of Scientific Information on Social Sciences RAS, №3, 73-89.

Torfing, J. (1999). New Theories of Discourse. Laclau, Mouffe and Zizek. Oxford: Blackwell.

Vepreva, I.T. (1999). On the social-evaluation function of metalinguistic comments in a public speech. Political discourse in Russia-3: Proceedings of the workshop. M., 51.

Vinogradov, V.S. (2001). Introduction to Translation Studies (general and lexical questions). M.: Institute of general secondary education RAS Press.

Vladimirova, E.V. (2003). Background knowledge as a semantic category in communicative-pragmatic aspect. Author's abstract to thesis ... Candidate of Philology. M., 12-13. 
